\section{Unavoidable deaths in the Italian Emergency Departments. Results of a ten-year survey. A mirror of substantial social
changes, or a warning for
a hospital-system pathology?}

\author{
Gianfranco Cervellin, ${ }^{1}$ Ivo Casagranda, ${ }^{2}$ \\ Giorgio Ricci, ${ }^{3}$ Ilenia Mezzocolli, ${ }^{4}$ \\ Ciro Paolillo, ${ }^{5}$ Rita Rossi, ${ }^{6}$ \\ Andrea Bellone, ${ }^{7}$ Stefano Guzzetti, ${ }^{8}$ \\ Fabrizio Giostra, ${ }^{9}$ Gianni Rastelli, ${ }^{10}$ \\ Mario Cavazza"1 \\ 'Emergency Department, University \\ Hospital of Parma, Parma; ${ }^{2}$ Emergency \\ Department, S.S. Antonio e Biagio e C. \\ Arrigo Hospital, Alessandria; ${ }^{3}$ Emergency \\ Department, University Hospital Borgo \\ Trento, Verona; ${ }^{4}$ Emergency Department, \\ University Hospital of Padua, Padua; \\ ${ }^{5}$ Emergency Department, University \\ Hospital of Udine, Udine; ${ }^{6}$ Emergency \\ Department, Hospitals of the Province of \\ Teramo, Teramo; ' ${ }^{7}$ mergency Department, \\ Niguarda Hospital, Milan; ${ }^{8}$ Emergency \\ Department, Luigi Sacco Hospital, Milan; \\ ${ }^{9}$ Emergency Department, Murri Hospital, \\ Fermo; ${ }^{10}$ Emergency Department, Vaio \\ Hospital, Fidenza (PC); ${ }^{11}$ Emergency \\ Department, S. Orsola Malpighi University \\ Hospital, Bologna, Italy
}

\section{Abstract}

Emergency departments (EDs) are increasingly used for patients at the end of life stage of their diseases worldwide, even if they do not have acute and potentially treatable conditions. Moreover, an increasingly shortage of hospital beds, in spite of the well-recognized ageing of the population, has led to a progressive prolongation of the average length of stay (LOS) time in the vast majority of Italians EDs. Therefore, the aim of this study was to describe the trend of ED non-traumatic deaths in 11 Italians EDs, and to correlate these deaths with the medium length of stay in the same EDs. All cases classified as died during ambulance transfer or while in the ED have been retrieved from the hospital database of the 11 participating EDs, from January 1st 2007 to December 31st 2016, with the exclusion of traumatic events. The average LOS in minutes of the seven hospitals that could provide this information was then calculated. A continuously increasing number of ED deaths was observed in the vast majority of participating EDs, showing a nearly $30 \%$ increases in the last four years. The average LOS of the vast majority of participating hospitals displayed a significant increase during the observational period. We also found a linear correlation between average LOS and total number of ED deaths in the same seven hospitals. We believe that there is a compelling need to reconsider the end of life trajectories, not only under an economical perspective, but mainly according to a more ethical view.

\section{Introduction}

Death is obviously unavoidable. People die from many different causes, in many different ways, and in many different environments. When asked about their preferences, most individuals would say that they prefer, at the end of their life, to be sided by the family, preferably in a familiar setting. Despite this consideration, emergency departments (EDs) are increasingly used for patients at the end of life stage of their diseases worldwide, even if they do not have acute and potentially treatable conditions. Nevertheless, frequently they receive increasingly intensive and often invasive care. ${ }^{1,2}$ Several clinical, social and economic factors, that have been discussed elsewhere, should be considered as main determinants of this occurrence..$^{3-7}$

The emergency physicians (EPs) and emergency nurses (ENs) not only manage the process of dying in the ED for patients with acute diseases or injury-related terminal events, but also increasingly care for those dying from chronic, end stage diseases. Due to the progressive aging of the population, the number of patients with chronic, serious or end-stage illnesses who present to the ED is expected to considerably increase in the future..$^{8-10}$

Most of us would agree that some patients experience a dying process that does not comply with the common perception of a good death at end of their life.,.$^{211-13}$

A comprehensive framework to improve care for the dying persons has been developed a couple of decades ago by the US Institute of Medicine (IOM): A decent or good death is the one that is: free from avoidable distress and suffering for patients, families, and caregivers; in general accord with patients' and families' wishes; and reasonably consistent with clinical, cultural, and ethical standards. The IOM framework is comprehensive of some initiatives aimed to improve the care of the dying, but these models are seemingly scarcely used in the ED. ${ }^{13}$ The main purpose of emergency medicine (EM) is to treat
Correspondence: Gianfranco Cervellin, Emergency Department, Academic Hospital of Parma, 43126 Parma, Italy.

Tel: +39.0521 .703800 - Fax: +39.0521 .703144 . E-mail: gianfranco.cervellin@gmail.com; gcervellin@ao.pr.it

Acknowledgements: the Authors acknowledge Drs. Lucia Antolini, Loris Pietracci, Angela Stazzone, Gianna Vettore, Cristian Zanelli, for the kind support in extracting data from electronic databases of their Institutions.

Key words: Death; Emergency department; Palliative care; End of life; Length of stay.

Received for publication: 20 March 2017

Revision received: 4 April 2017.

Accepted for publication: 4 April 2017.

This work is licensed under a Creative Commons Attribution 4.0 License (by-nc 4.0).

(C) Copyright G. Cervellin et al., 2017

Licensee PAGEPress, Italy

Emergency Care Journal 2017; 13:6718

doi:10.4081/ecj.2017.6718

patients across all ages and disease or injury spectra, in a definite time window, with the aim of stabilize patients and finally discharging or admitting them to an appropriate facility. Among several similar definitions, for example, the American College of Emergency Physicians (ACEP) defines the specialty of EM as a medical specialty dedicated to the diagnosis and treatment of unforeseen illness or injury. ${ }^{14-18}$

According to the World Health Organization (WHO), between 2015 and 2050 , the proportion of the world's population over 60 years will double, and by 2050 there will be more than 400 million people aged 80 and older worldwide. Notably, among the elderly population, only $15 \%$ of all deaths are due to an acute disease or trauma, whereas $85 \%$ are related to chronic diseases. ${ }^{19}$

In Italy also there is a widespread perception of incresing rates of hospital deaths, in particular regarding deaths in the ED for chronic, end stage diseases (i.e., cancer, dementia, terminal illness), but defintive data on this subject are lacking. Moreover, an increasingly shortage of hospital beds, in spite of the well recognized ageing of the population, has led to a progressive prolongation of the average length of stay (LOS) time in the vast majority of Italians EDs. Therefore, the aim of this study was to describe the trend of ED deaths in 11 Italians EDs, and to correlate these deaths with the medium length of stay in the same EDs. 


\section{Materials and Methods}

All cases classified as died during ambulance transfer or while in the ED have been retrieved from the hospital electronic database of the 11 participating EDs, from January $1^{\text {st }} 2007$ to December $31^{\text {st }} 2016$, with the exclusion of traumatic events. Unfortunately, since some EDs could not identify the information throughout the study period, in a number of cases data are only partial.

The patients' volumes and the average LOSs of the participating EDs in the year 2016 are shown in Table 1.

The total number of non-traumatic deaths occurred during ambulance transfer or while in the ED was calculated in each hospital separately, and then put together as a sum of all hospital data, beginning from year 2013 (i.e., the first year in which all hospitals could provide precise information).

The average LOS in minutes (defined as the time lasting from first medical contact to discharge from the ED, both at home or to a hospital ward) of the seven hospitals that could provide this information was then calculated. Starting from year 2010 (i.e., the first year in which these seven hospitals could provide precise information), the average LOS of the entire sample was then calculated by summing the average LOS of each ED, and then diving the result by seven (i.e., the number of EDs), on a yearly basis. The average LOSs of the seven hospitals was then associated with the total number of deaths in the same EDs by univariate linear regression analysis, using the program Mathematica9 ${ }^{\circledR} \quad$ (Wolfram, Champaign, IL, US). The $t$ statistics are the estimates divided by the standard errors.
The $\mathrm{p}$-value is the two-sided $\mathrm{P}$ value for the $t$ statistic and can be used to assess whether the parameter estimate is significantly different from zero. In particular, the following statistical analysis was obtained: univariate linear regression analysis between average LOS in seven EDs and total number of deaths in the same EDs, in the years 20102016.

Due to the retrospective nature of the study and the maintenance of anonymity of all subjects, the consensus of the ethical committee was unnecessary. The study was performed in accordance with the Declaration of Helsinki, under the terms of relevant local legislation.

\section{Results}

As shown in Figure 1, a continuously increasing number of ED deaths was observed in the vast majority of participating EDs.

When summing all ED deaths of participating hospitals from 2013 (i.e., the first year in which all the hospitals could provide precise and complete information), the trend seems even clearer, showing a nearly $30 \%$ increases in four years (Figure 2). The average LOS of the vast majority of participating hospitals displayed a significant increase during the observational period, with significant inter-center heterogeneity (Figure 3).

When several hospitals were considered altogether, the incremental trend seems again more accentuated. We have hence calculated the average LOS of the seven hospitals providing this information from the 2010 (i.e., the first year in which seven hospitals could provide precise data). The result of this analysis is shown in Figure 4.

Table 1. Patients census and average length of stay of the participating emergency departments in the year 2016 .

\begin{tabular}{lcc}
\hline ED & Number of ED visits, year 2016 & Average LOS, year 2016 \\
Parma University Hospital & 113714 & 306 \\
Bologna S. Orsola Hospital & 142404 & 285 \\
\hline Milan Niguarda Hospital & 92347 & NA \\
Milan Sacco Hospital & 50925 & 288 \\
\hline Verona Borgo Trento Hospital & 134175 & 219 \\
Padova University Hospital & 85680 & 230 \\
\hline Udine University Hospital & 61590 & NA \\
Alessandria Hospital & 42561 & 246 \\
\hline Teramo Hospital & 122759 & 195 \\
Fermo Hospital & 37187 & 234 \\
\hline Fidenza Hospital & 32619 & 167
\end{tabular}

ED, emergency department; LOS, length of stay.

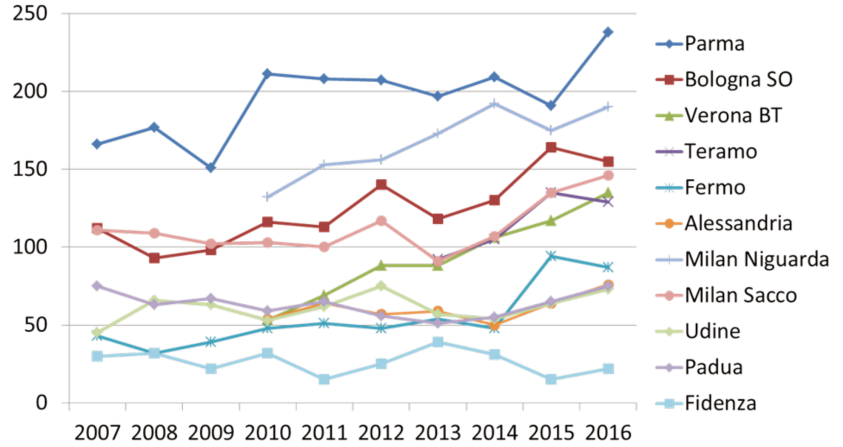

2007200820092010201120122013201420152016

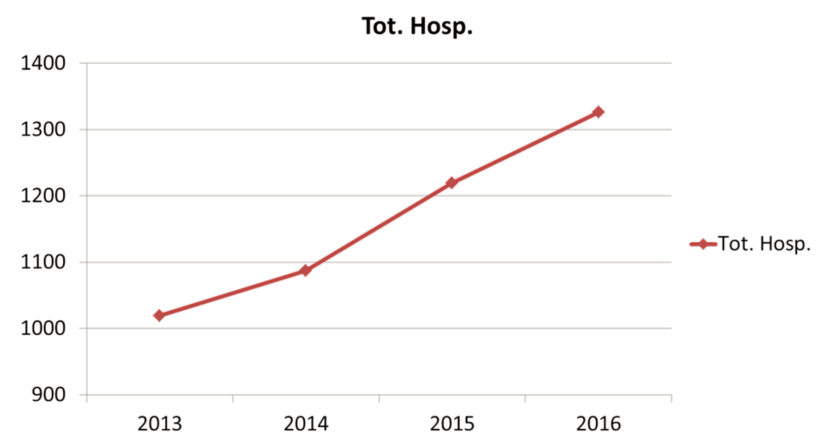

Figure 1. Number of patients deceased in the emergency departments of the eleven involved Hospitals, years 2007-2016.
Figure 2. Total number of patients deceased in the emergency department: sum of the eleven hospitals' data, years 2013-2016. 
We also found a non-significant linear correlation between average LOS and total number of ED deaths in the same seven hospitals $\quad(y=-186.26+5.005 x ; \quad R=+0.974$; $\mathrm{P}=0.188$ ) (Figure 5).

\section{Discussion}

A crisis in end of life care for older adults is occurring in many countries of the so-called western world. Too often patients receive unwanted care that causes additional sufferance without significantly improving duration or quality of life.

Up to $70 \%$ of older patients present to $\mathrm{ED}$ at least once in the last 12 months of their life in the western world, a rate increasing in their final weeks and days. ${ }^{20}$ The end of life represents a continuous challenge for EPs, and care is administered with a wide range of quality. ${ }^{21,22}$ As such, the ED has been increasingly recognized as an essential environment for initiating palliative care over the past decades. ${ }^{23,24}$
A large Australian survey clearly support the need and desire for greater integration of values and standards of palliative care in EDs, a fact that prompted the authors to rhetorically reply to the responders with Do patients die well in your emergency department? ${ }^{25}$ When caring for dying patients in a busy and crowded ED, many challenges arise that probably do not exist when the patient are in their home or even in a hospital ward. The fact that the patient is dying in the ED does not mean that she/he does not need the maximum amount of dignity and respect possible. All doctors, so including EPs, should always keep in mind the principle To cure sometimes, to relieve often, to comfort always.

Despite policymakers and healthcare professionals tend to believe that people prefer dying at home, the majority of deaths occur in the hospital environment (e.g., the rate is as high as $66 \%$ in the United Kingdom), ${ }^{26}$ a third of which occurring in the first few hours of hospital admission, often still in the ED. ${ }^{27}$

More than one century ago, in 1908, Sir
William Osler carried out an important study of sequential hospital death in the US. ${ }^{28}$ After analyzing 486 deaths at John Hopkins Hospital, Osler summarized his findings with the statement that 90 suffered bodily pain or distress, 11 showed mental apprehension. The great majority gave no sign one way or the other like their birth their death was a sleep and a forgetting. After this study, a large part of literature and research about the modern attitude to death seems to criticize the trend to increasing hospital deaths, since it resembles a threat to an idealized good death. ${ }^{29}$

Some Authors perceive that an increasing number of elderly patients is referred to the ED at the end of life, often from nursing homes and without any real medical perspective. These patients are simply dying, and the only need they have is to mitigate sufferance. This fact has been clearly demonstrated in a recent study published by a team of Italian general practitioners (Figure 6). ${ }^{30,31}$ Nevertheless, this information is based on hospital deaths, whereas less information is available about ED

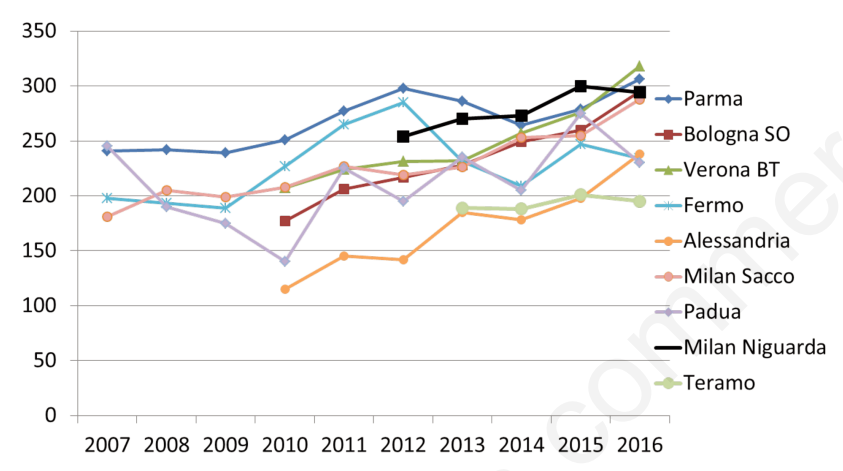

Figure 3. Average length of stay (in mins) of seven hospitals, years 2007-2016.

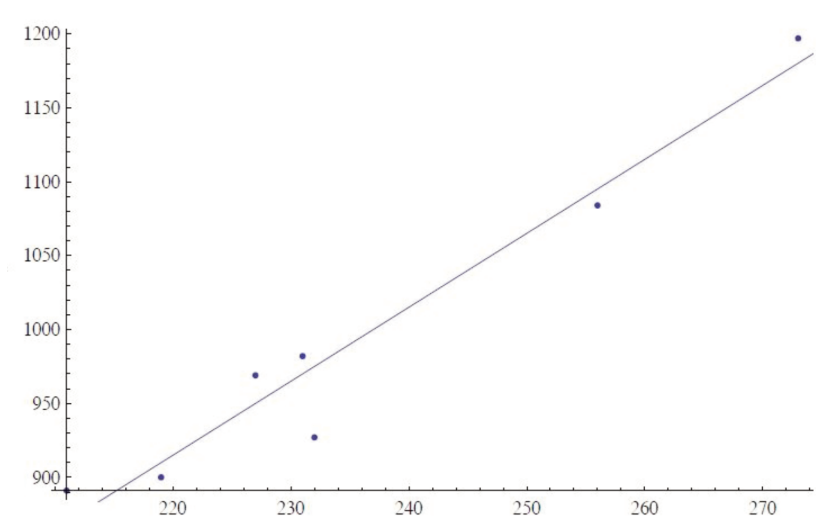

Figure 5. Linear regression analysis between average length of stay (in mins) and total number of deaths in seven selected emergency departments. $y=-186.2 ; 6+5.005 x ; R=+0.9742 ; P=0.188$.

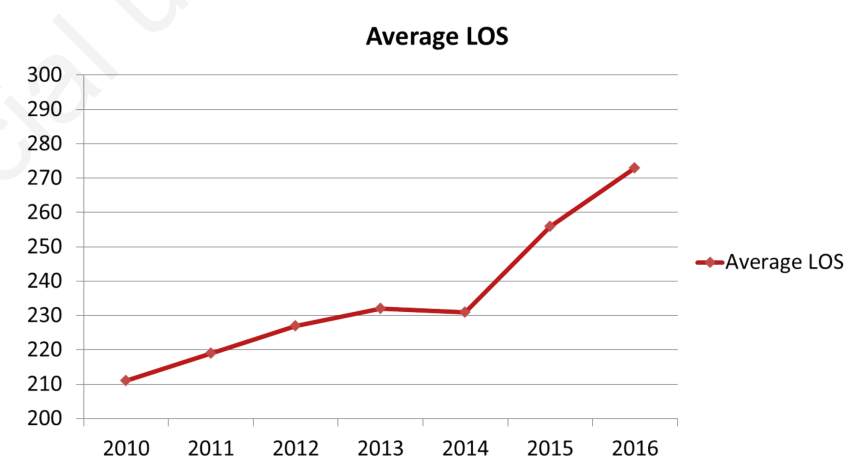

Figure 4. Average length of stay (in mins): average of the seven hospitals with available data, years 2010-2016.

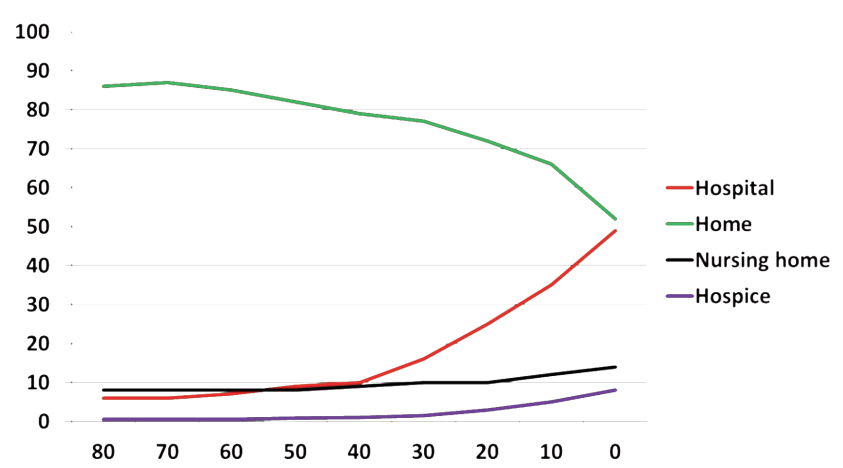

Figure 6. Where do Italian patients die: place shift in the last weeks/days before death. $x$ axis: days before death; $y$ axis: percentage of patients. 
deaths in Italy. To further address this important aspect we tried to collect data from some EDs in Central and Northern Italy. Unfortunately the electronic databases of the different facilities are not uniformly designed and in some cases they are still under development. Therefore, not all the EDs could retrieve full information throughout the study period. This accounts for the partial and often heterogeneous information.

Even considering these limitations, our results clearly show that: i) there is an increasing number of people dying in the ED; ii) the increasing LOS observed in Italian EDs, largely due to the continuous reduction of hospital beds, is strongly (although not significantly, due to the paucity of data) correlated to an increasing number of deaths. Taken together this evidence demonstrates that the EDs are increasingly seen as places in which unavoidable deaths occur, and EPs should hence enhance their skills for facing terminal diseases leading patients to death.

As in other countries, ${ }^{14,15,32}$ a large number of elderly patients finish their lives in Italian EDs also, and the majority are probably admitted to the hospital despite the assumption that they are obviously dying and that medicine has very little to offer. Therefore, we believe that there is a compelling need to reconsider the end of life trajectories, not only under an economical perspective, but mainly according to a more ethical view.

\section{Conclusions}

In other words, rephrasing a famous article, ${ }^{33}$ we could conclude asking ourselves: Are the dying patients and their families our honored guests in our EDs? Are the EDs in which we work honored places for them?

\section{References}

1. Hillman K. Dying safely. Intern J Qual Health Care 2010;22:339-40.

2. Wright AA, Keating NL, Balboni TA, et al. Place of death: correlations with quality of life of patients with cancer and predictors of bereaved caregivers' mental health. J Clin Oncol 2010;28: 4457-64.

3. Kardamanidis K, Lim K, Da Cunha C, et al. Hospital costs of older people in New South Wales in the last year of life. Med J Austr 2007;187:383-6.

4. Moorin RE, Holman CDJ. The cost of in-patient care in Western Australia in the last years of life: a population based data linkage study. Health Policy 2008;85:380-90.

5. Billings JA, Krakauer EL. On patient autonomy and physician responsibility in end-of-life care. Arch Intern Med 2011;171:849-53.

6. Roch A, Wiramus S, Pauly V, et al. Long-term outcome in medical patients aged 80 or over following admission to an intensive care unit. Crit Care 2011;5:R36.

7. Russell C, Middleton H, Shanley C. Dying with dementia: the views of family caregivers about quality of life. Australas J Ageing 2008;27:89-92.

8. Roberts DC, McKay MP, Shaffer A. Increasing rates of emergency department visits for elderly patients in United States, 1993 to 2003. Ann Emerg Med 2008;51:769-74.

9. Grudzen CR, Richardson LD, Morrison $\mathrm{M}$, et al. Palliative care needs of seriously ill, older patients presenting to the emergency department. Acad Emerg Med 2010;17:1253-7.

10. Barbera L, Taylor C, Dudgeon D. Why do patients with cancer visit the emergency department near the end of life? CMAJ 2010;182:563-8.

11. Emanuel EJ, Emanuel LL. The promise of a good death. Lancet 1998;351:21-9.

12. Hales S, Zimmermann C, Rodin G. The quality of dying and death. Arch Intern Med 2008;168:912-8.

13. Institute of Medicine. Approaching death: improving care at the end of life. Washington, DC, USA: Institute of Medicine; 1998.

14. Le Conte P, Baron D, Trewick D, et al. Withholding and withdrawing life-support therapy in an Emergency Department: prospective survey. Intens Care Med 2004;30:2216-21.

15. Le Conte P, Riochet D, Batard E, et al. Death in emergency departments: a multicenter cross-sectional survey with analysis of withholding and withdrawing life support. Intens Care Med 2010;36:765-72.

16. Girbes ARJ. Dying at the end of your life. Intens Care Med 2004;30:2143-4.

17. American College of Emergency Physicians (ACEP). Definition of emergency medicine. Available at: https://www.acep.org/ClinicalPractice-Management/ Definition-ofan-Emergency-Service/

18. O'Connor AE, Winch S, Lukin W, et al. Emergency medicine and futile care: taking the road less travelled. Emerg Med Australas 2011;23:640-3.

19. World Health Organization (WHO). 10 facts on ageing and health. Available at: www.who.int/features/factfiles/ageing/ en/

20. Rosenwax LK, McNamara BA, Murray $\mathrm{K}$, et al. Hospital and emergency department use in the last year of life: a baseline for future modifications to end-oflife care. Med J Australas 2011;194:570-3.

21. Todd KH. Practically speaking: emergency medicine and the palliative care movement. Emerg Med Australas 2012;24:4-6.

22. Lukin W, Douglas C, O'Connor A. Palliative care in the emergency department: an oxymoron or just good medicine? Emerg Med Australas 2012; 24:102-4.

23. Russ A, Mountain D, Rogers IR, et al. Staff perceptions of palliative care in a public Australian, metropolitan emergency department. Emerg Med Australas 2015;27:287-94.

24. Shearer FM, Rogers IR, Monterosso L, et al. Understanding emergency department staff needs and perceptions in the provision of palliative care. Emerg Med Australas 2014;26:249-55.

25. Bradley V, Burney C, Hughes G. Do patients die well in your emergency department? Emerg Med Australas 2013;25:334-9.

26. Costello J. Dying well: nurses' experiences of "good and bad" deaths in hospital. J Adv Nurs 2006;54:594-601.

27. Yates DW, McGuiness S. Care of the suddenly bereaved. BMJ 1999;301:2930.

28. Lynn J, Teno J, Phillips RS, et al. Perceptions by family members of the dying experience of older and seriously ill patients. Ann Intern Med 1997;126:97-106.

29. Smith R. A good death. An important aim for health services and for us all. BMJ 2000;320:129-130.

30. Bertolissi S, Miccinesi G, Giusti F. Come si muore in Italia. Storia e risultati dello studio Senti-MELC. Rivista Soc Ital Med Gen 2012;2:17-34.

31. Giorgi Rossi P, Beccaro M, Miccinesi $\mathrm{G}$, et al. Dying of cancer in Italy: impact on family and caregiver. The Italian Survey of Dying of Cancer. J Epidemiol Comm Health 2007;61:547-54.

32. Forero R, McDonnell G, Gallego B, et al. A literature review on care at the end-of-life in the emergency department. Emerg Med Intern 2012; 2012:486516.

33. Donnelly S. Patient dying in hospital: an honoured guest in an honoured place? QJ Med 2013;106:697-700. 